\title{
Parental Experiences of a Cerebral Palsy Clinic in a PoOr URbanizing COMMUNity
}

\begin{abstract}
Fifty-five parents of children with cerebral palsy (CP) attending the CP Clinic at Baragwanath Hospital were randomly selected and interviewed. An open-ended, semi-structured verbal questionnaire was used to determine the parents' understanding of their child's diagnosis, their hopes and expectations and their impressions of the therapy service offered by the clinic. All parents attending the clinic for the first time were excluded. Results showed that although an explanation of the diagnosis had been given to 54 of the participants, only $40 \%$ gave a medical explanation for their child's problems. In all cases this explanation was brief and incomplete. Most parents (87\%) were still hoping for a normal outcome.
\end{abstract}

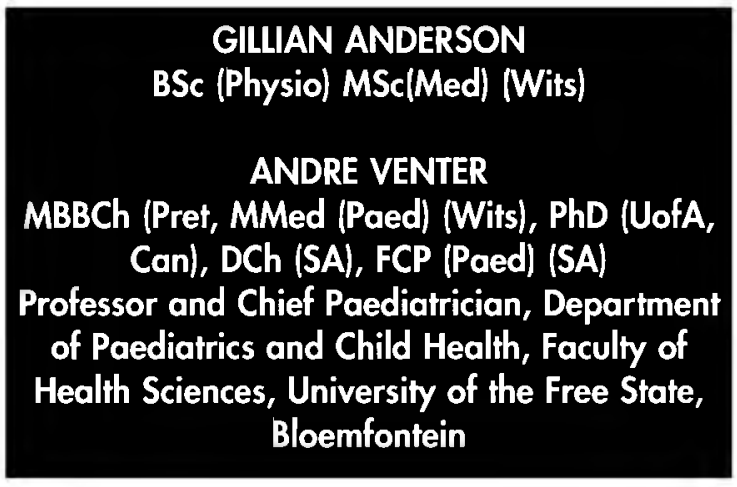
Seventy-three percent of parents wanted their children to "be like other children" and 18\% saw walking as a shortterm goal. Economic independence and the ability to fulfil a parental role were the most common long-term goals. Eighty-four percent stated they would continue to attend the clinic even if the therapy was not helping their children. Home visits were thought to be a good idea by the majority (82\%) of parents. The study demonstrated that parents' understanding of $C P$ was vague, and their hopes for their children's future unrealistic. As the majority of children attending the clinic were still young, the parents' hopes for a normal child may not be that unrealistic. Parents were generally satisfied with the service provided but this may reflect their disempowerment. The need for appropriate education of parents regarding diagnosis, outcome and services available is highlighted, as are the needs for establishing mutual goals in therapy, and empowering parents.

\section{KEYWORDS: PERCEPTIONS, EXPECTATIONS, HOME MANAGEMENT, THERAPY, CEREBRAL PALSY}

$\mathrm{T}$ The impact of a child with a disability on a family is complex and cannot easily be described or predicted $^{1}$. For health and therapeutic services to maximally satisfy the needs of these families, it is necessary to establish what their needs and expectations are. There is evidence that the needs of parents with disabled children differ from those perceived by professional health workers. ${ }^{23}$ Studies done in America and the United Kingdom highlight the importance of individualized service and treatment plans tailored to varying family strengths and needs. ${ }^{4.5}$ Services which focus on the child's disability often may not address other problems in the family. In some cases, the services themselves may produce extra demands on the family by expecting parents to concentrate on the child with the disability to the exclusion of other problems. ${ }^{2}$

Limited resources in developing countries results in families of children with a disability often receiving little or no assistance with the care, education and training of their disabled child. ${ }^{6}$ The WHO estimates that in developing countries, existing services are meeting no more than two percent of those in need.
In South Africa, less than half of people with a disability receive rehabilitation and only five percent receive professional help at home to enable them to cope better with the disability.

Baragwanath Hospital is a state-run hospital which serves Soweto, a predominantly poor, urbanising, black community with an estimated population of over two million people. The Cerebral Palsy (CP) Clinic at the hospital is the only outpatient facility offering therapy to children with CP living in Soweto and the surrounding areas. During the past 5 years, approximately 2000 children with $\mathrm{CP}$ have been referred for therapy. Most children attend the clinic monthly and the main form of therapy offered is a home management programme which is based on neuro developmental therapy principles. Thus the role of parents in caring for their children at home is vital. The aim of the home programme is to facilitate easier management of the child in his own environment in a way which benefits the child without increasing the burden of care.

Dyer ${ }^{3}$ showed that there is a difference in the view of parents and therapists of the difficulties experienced in caring for a child with $\mathrm{CP}$. Therapists consistently underestimated the problems perceived by parents and overall agreement between therapists and parents was only $38 \%$. The findings indicated that for parent participation to improve, therapists needed to alter their practise so as to be more aware of the parents' views and concerns in relation to the care of their child with $\mathrm{CP}$.

Although parental involvement has been a major development in the field of disability, there has been relatively little systematic investigation of the value of parental involvement from the parents' point of view, ${ }^{5}$ especially from a cross cultural perspective and working in a disadvantaged and deprived environment.

Harry $^{9}$ examined the role of culture in Puerto Rican parents' interpretations of their children's placement in special schools. Parents showed conflicting interpretations of the concept of disability and offered alternative explanations for their children's learning difficulties. The study demonstrated that consequently, the power and the potential of parents as effective collaborators in the education process was seriously undermined. Lynch and Stein ${ }^{10}$ point out that in 


\section{TABLE I}

\section{PARENTAL HOPES FOR THEIR CHILD}

\section{HOPE EXPRESSED}

Hope that my child will become normal

Do not think that my child will be normal

No hope at all

Total

$\begin{array}{cc}\text { NUMBER } & \% \\ 48 & 87 \\ 6 & 11 \\ 1 & 2 \\ 55 & 100\end{array}$

disadvantaged groups, the process of service provision itself may be in direct conflict with the family's cultural values and beliefs. When working with families of children with disabilities, the parents' contribution to defining the problem is often disregarded. Professionals are regarded as having both the expertise and authority to identify both the problems and the solutions. " Conflict may arise between disadvantaged minority groups of parents who are seeking the authority to determine the services their children need, and the professionals who define their own roles as experts. In disadvantaged and disenfranchised communities the unequal distribution of power is exacerbated. ${ }^{12}$ In such a relationship the parents' of the child with a disability are further disempowered.

The present service offered at the $\mathrm{CP}$ Clinic is based on a traditional western multidisciplinary model despite it serving a developing and disadvantaged community. The therapists at the clinic are fully aware of the divergent cultures and belief systems of their patients and make every effort to explain the child's condition to the parents in a culturally acceptable manner, but still using western medical concepts. This approach has been assumed to be appropriate but no work has previously been done to establish the parents' perception of their child's disability, their expectations for their children, their need for help and why they were using the service. This study endeavoured to provide answers to these questions.

\section{METHOD}

All parents or caregivers of children where a diagnosis of CP had been confirmed by clinical examination and who had attended the CP Clinic at least once previously were selected over a random three week period. Anonymity and confidentiality were guaranteed and consent was obtained from participants before the questionnaire was administered. An open-ended, semi-structured verbal questionnaire was used asking the following questions:

1. Has anybody explained to you what the problem with your child is? If so, who?

2. What do you think is wrong with your child?

3. What are your hopes for your child?

4. Do you think your child will achieve this?

5. What do you think the CP Clinic can do for

i. you?

ii. your child - in the short term?

iii. in the long term?

6. Do you talk to other mothers when you are waiting for therapy?

7. Does this help you to manage your child?

8. Do you think it is important to come to the CP Clinic for therapy? Why?

9. If you thought that therapy was not helping, would you still come?

10. How often would you like to attend therapy at the CP Clinic?

11. Do you think it would help you if someone from the CP Clinic came to visit you and your child at home? Why?

12. Do you think there is anything else at the CP Clinic which we can do to help you and your child?

The questions focused on the parents' understanding of their child's diagnosis, their short and long-term hopes and expectations for the child, and their impressions of the service and therapy offered at the CP Clinic. The interview was conducted in one of the local languages (eg. Sotho, Zulu) by an impartial non-medical research assistant who had no particular knowledge of the child's condition. All the answers were recorded verbatim in English by the interviewer.
These answers were then categorised by the primary researcher, who was blind to the child's diagnosis and the identity of the parents. Statistical analysis was made using Statpac.

\section{RESULTS}

Fifty-five interviews were conducted with the majority ( $84 \%$ ) being with the child's mother. In only one case was an unrelated caregiver interviewed. Most (55\%) of the children came from the greater Soweto area, while $43 \%$ travelled from an area further than $50 \mathrm{~km}$ from the hospital. The vast majority ( $98 \%$ ) of children were under five years of age with over half being under the age of three years. Attendance at the clinic varied from less than a year to two years or longer. Most of the children $(83 \%)$ had attended the clinic for therapy on more than three occasions.

\section{PARENTAL PERCEPTIONS, HOPES AND EXPECTATIONS}

Fifty-four (of the 55) participants indicated that prior to this interview, a health worker had given them an explanation of their child's condition. In $82 \%$ of cases, this was the doctor and in $18 \%$ of cases, it was other clinic staff (a registered nurse or a therapist). When asked to describe their child's problem, most parents $(56 \%)$ explained it in terms of a functional disability - that the child's main problem was that he or she could not walk, talk or sit. Only $40 \%$ of the parents could advance a medical explanation for their child's problems, eg. the child did not get enough oxygen at birth (asphyxia), or that he or she had had meningitis, or simply that "the brain was damaged". In all cases, parents' explanations were brief and incomplete with no understanding of the link between the disability and its underlying pathology. This emphasises the fact that functional milestones such as sitting or walking are foremost in the minds of parents.

Most $(n=48)$ of the parents interviewed expressed the hope that their children would eventually be normal, six parents did not think that their child would be normal and one parent had no hope at all (Table 1). On further questioning, $60 \%$ of this group of parents believed that this was possible, $36 \%$ were unsure but hopeful, whilst $4 \%$ refuted the possibility of their child ever being normal.

Parents' most important short-term goal for their child was to see the child being able to do "the basic things of life - like other children". Eighteen percent 
saw walking as an important short-term goal while economic independence and the ability to fulfil his or her role as a parent were the two most common longterm goals mentioned (Table II). When asked about what they thought the clinic could do for them personally, $91 \%$ said they expected the clinic to assist them to help their children whilst seven percent felt that the clinic could do nothing for them as parents.

All of the parents agreed that it was important for them to come to the clinic. Two-thirds of parents had noticed improvement in their children. Of note was that $84 \%$ stated that even if they thought that therapy was not helping their children, they would continue to attend the clinic. Reasons given were that the clinic was perceived to be the only place where they could receive help for their child (22\%); that it would take a long time to see progress in their child and therefore it was important to continue attending; that they needed the support of other mothers they met at the clinic, or that they believed that their child would deteriorate if they stopped therapy.

Almost all the parents interviewed (96\%) talked to other parents whilst waiting for therapy with $78 \%$ indicating they found this beneficial as they gained advice, help, hope and encouragement from other mothers. However, $16 \%$ stated they did not find talking to other mothers helpful, as not all mothers were willing to discuss their children. Some parents also experienced communication difficulties owing to language differences.

When asked if they thought that home visits by therapists would be useful 45 mothers agreed. The reasons given were that this would mean that their children would get therapy more often $(38 \%)$, the therapist would evaluate the home environment and then modify the programme $(24 \%)$, the child would be more free at home $(18 \%)$, there was no money for transport to come to the clinic (13\%) and it would encourage the mother $(7 \%)$.

\section{DISCUSSION}

The study was useful in clarifying parental perceptions and understanding of their childrens' problems. It was clear that parents did not fully understand the underlying causes for their children's disabilities even though they had been offered an explanation. The understanding of the relationship between brain injury and the consequent physical prob- lems and loss of function was vague. It is possible that the explanations parents were given were too brief, too detailed, or inappropriate. All the parents who participated in the study had attended the Clinic for therapy more than once and therapists assumed that they understood what a diagnosis of $\mathrm{CP}$ meant. However, it appears that a prior knowledge of the child's diagnosis should not be taken for granted. A greater emphasis needs to be placed on providing parents with an explanation which they can understand. Yet, on the other hand, it has been well documented that a parents' emotional responses to the news of their child's disability makes it difficult for them to grasp the implications and consequences of the explanations offered. ${ }^{13.14 .15}$ Feelings of shock, denial or anger may inhibit parents form absorbing the explanation or from asking questions.

In this study, no alternative explanations (eg. bewitchment, genetics), for the child's disability were suggested by the parents. Although this was surprising, it does not imply that parents had not sought help from traditional healers. As the children were receiving therapy in a hospital environment, it is possible that parents felt constrained about discussing alternative treatments or traditional beliefs. It would be useful if future questionnaires included questions on these subjects.

The parents' expectation and hope for a normal child was a dominant and not unexpected feature. These expectations were unrealistic considering that their children were severely disabled and many had been attending the CP Clinic for over a year. At present, the main service offered at the clinic is therapy. As therapy focuses on facilitating the child's ability to do things for himself, the parent may feel encouraged and thus therapy itself may contribute to the parents' unrealistic hopes and high expectations. Alter-natively, as it has just been shown that the parents do not have a clear understanding of the diagnosis, it is not surprising that their prognosis is unrealistic. High parental hopes for a normal child are not uncommon in any society. ${ }^{13}$

The predominance of infants and
TABLE II

\section{PARENTAL EXPECTATIONS FOR THEIR CHILD}

\begin{tabular}{|l|r|r|}
\hline SHORT-TERM & NUMBER & $\%$ \\
Become like other children & 40 & 73 \\
Learn to walk & 10 & 18 \\
Attend school & 1 & 2 \\
Unsure & 1 & 2 \\
Other & 3 & 5 \\
Total & 55 & 100 \\
& & \\
\hline LONG-TERM & & \\
Economic independence & 22 & 40 \\
Have a family & 9 & 16 \\
Attend school & 8 & 15 \\
Good quality of life & 8 & 15 \\
Become normal & 3 & 5 \\
Other & 4 & 9 \\
Total & 55 & 100 \\
\hline
\end{tabular}

\section{TABLE III}

\section{REASONS FOR WANTING HOME VISITS}

\begin{tabular}{l|c|c|}
\hline $\begin{array}{l}\text { Means that child } \\
\text { gets more therapy }\end{array}$ & 17 & 38 \\
$\begin{array}{l}\text { Correct and advise } \\
\text { home programme }\end{array}$ & 11 & 24 \\
$\begin{array}{l}\text { Child is more "free" } \\
\text { at home }\end{array}$ & 8 & 18 \\
$\begin{array}{l}\text { No money for transport } \\
\text { to come to CP Clinic } \\
\text { Will encourage the mother }\end{array}$ & 3 & 13 \\
Total & 45 & 100 \\
\hline
\end{tabular}

young children (only $25 \%$ were over the age of two years) may also shed some light on the high parental expectations. It supports the impression of therapists working at the CP Clinic that initially parents will bring their children regularly, but as time passes and the child is still not "cured", or seems to have reached a plateau and progress is no longer obvious, the parents lose hope and stop coming. This assumption is confirmed by the finding that parents are unclear about their child's diagnosis and prognosis and that explanations given to parents appear 
to have been unsatisfactory. It would be interesting and valuable to establish what the hopes and expectations of parents are who have terminated therapy.

The results indicate that in general, parents were satisfied with the service they were receiving. It is surprising that $84 \%$ of parents said that they would still attend the clinic even if they thought that the therapy was not beneficial. This indicates the important subsidiary role the clinic plays in providing emotional help and support to parents and that therapy is only one component of what the clinic potentially offers to mothers. It also highlights the paucity of community-based services offering appropriate support and counselling to families of children with $\mathrm{CP}$. The availability of these resources could significantly impact on the care of disabled children, while reducing the workload for the clinic staff.

The need for more community involvement is further expressed by the parents' desire for home visits. The involvement of parents in therapy programmes at home is advocated and encouraged by most therapists. ${ }^{16.17 .18}$ There are however, conflicting opinions about the potential benefits and detrimental effects which this may have on both the child and the family. Home visits are often criticized as being timeconsuming and expensive in terms of staff utilisation and work production. However, as a result of this study, home visits to children living in Soweto have been introduced by the clinic staff and this programme is currently being evaluated.

The study has a number of limitations which should be borne in mind when interpreting the results. To ensure confidentiality, trust and honestly, respondents were not identified. This made it impossible to correlate the nature and severity of the child's disability with the parents' understanding of the disability, their hopes and their expectations. In addition, this study did not evaluate the actual service being provided. Parents may have been satisfied with suboptimal information and care because of poor education, disempowerment and low life expectations. As the interview was conducted in the local languages, some information may have been lost or modified during the translation and recording into English. The findings could also be biased by the use of the clinic setting to conduct the interviews, and only interviewing parents who used the service.

\section{CONCLUSION}

This study demonstrates that at the CP Clinic at Baragwanath Hospital, parents' knowledge of their children's disability and their hopes and expectations for their children's future are often vague and unrealistic. This was irrespective of the length of time they attended therapy and despite the fact that the condition had been explained to them. Appropriate education of parents bringing their children to the CP Clinic is critical. Not only do parents require continuous education and knowledge about $\mathrm{CP}$ and the likely outcome for their children, but also information with regard to services and therapy offered, and what can be expected from the clinic.

The need for a partnership between therapists and parents in establishing mutual needs and goals is important. Empowering children with a disability and their families is essential if they are to take charge of their own lives. Empowerment creates opportunities for families to gain access to resources and to acquire the necessary knowledge and skills to cope better with the disability. This enables families to actively participate in the decision-making process and evaluate the service provided to their children.

The information and insight gained from this study is already being utilized to change the service offered to parents who bring their children to the CP Clinic. Apart from introducing home visits, there is now more emphasis on support and self-help groups, and a review of the explanations parents are given with regard to their child's diagnosis and prognosis has been made.

Future research will focus on those parents who have stopped attending the clinic. Their views would probably more accurately reflect the long-term satisfaction with, and perception of services and identify possible disillusionment with the clinical outcome.

\section{ACKNOWLEDGEMENT}

We wish to thank Dr. Haroon Saloojee for reading the draft and for his valuable comments.

\section{REFERENCES}

1. Erickson $\mathrm{M}$ and Upshur C. Caretaking burden and social support: Comparison of mothers of infants with and without disabilities. American Journal of Mental Retardation 1989;94(3): 250258.

2. Sloper P and Turner S. Service needs of families of children with severe physical disability. Child-care, health and development 1992;18: 259-282.

3. Dyer S. Caring for a child with cerebral palsy: A comparison of therapists' and parents' perceptions. 1992. Unpublished Masters dissertation. King's College, University of London.

4. Krahn GL, Eisert D and Fifield B. Obtaining parental perceptions of the quality of services for children with special health needs. Journal of Pediatric Psychology 1990;25(6): 761-774.

5. Dale NJ. Parental involvement in the KIDS family centre: Who does it work for? Child-care, health and development 1992;18: 301-319.

6. O'Toole B. A community-based rehabilitation programme for pre-school disabled children in Guyana. International Journal of Rehabilitation Research 1988; 1 1(4): 323-334.

7. World Health Organization. Report of a WHO Consultation on Community-Based rehabilitation. 28 June - 3 July 1982, Colombo, Sri Lanka, RHB/lR/82.1. Geneva: WHO, 1982.

8. Hirschowitz R and Orkin M. A national household survey of health inequalities in South Africa. Prepared by The Community Agency for Social Enquiry (CASE) for the Henry J Kaiser Family Foundation. 1995.

9. Harry B. Making sense of disability: Low-income, Puerto Rican parents' theories of the problem. Exceptional Children 1992;59(1): 27-40.

10. Lynch EW and Stein RC. Parent participation and by ethnicity: A comparison of Hispanic, black and Anglo families. Exceptional Children 1987;54: 105-111.

11. Kalyanpur M and Rao SS. Empowering low-income black families of handicapped children. American Journal of Orthopsychiatry 1991:61(4): 523-532.

12. Cummins J. Empowering minority students: A framework for intervention. Harvard Educational Review 1986;56: 18-26.

13. Hall M. But what do we tell the parents? Health Visitor $1987 ; 60 ; 110-112$.

14. Hodapp RM, Dykens EM, Evans DW, Merighi Jr. Maternal emotional reactions to young children with different types of handicap. Developmental and Behavioural Pediatrics 1992;13(2): $118-123$.

15. Kubler-Ross E. On death and dying. 1970. London: Tavistock.

16. Mackeith R. Advantages and Disadvantages. Dev Med Child Neurol 1976;18(2): 143-144

17. Finnie N. Handling the young cerebral palsied child at home. 2nd edition. Oxford: Heinemann medical Books.

18. Bobath $\mathrm{K}$ and Bobath B. The neuro-developmental treatment. In: Scrutton D, ed. Management of the motor disorders of children with cerebral palsy. Clinics in Developmental Medicine No. 90. Spastics International Medical Publications, 1984: 6-18. 